The eastern branch was fainter than the western, and at midnight it was seen from $\gamma$ Virginis, near the horizon, up to Præsepe in the zenith, as a broad and tapering cone of light.

Hence the zodiacal light, when seen in perfection, consists of two cones of light, whose common axis is the Ecliptic, and whose common vertex is a point on that axis almost exactly $180^{\circ}$ from the sun. The fact that the western branch is brighter than the eastern also confirms my idea of its origin, the brighter branch being over the warmer portion of the earth's surface; but I hope to make more observations of its breadth at different times of the year before writing more on this subject.

Jamaica, Feb. 6

MAXWELl Hall

[We hope our correspondent will continue to send us more of his interesting and valuable letters. It is indeed a great gain to science to have an observer stationed on the vantage ground which he occupies. - ED.]

As no one has replied to Maxwell Hall's letter on the zodiacal light (vol, vii. p. 203), I might state that his theory that the earth has two tails which stretch to an indefinite distance away from the sun is not in accordance with observation, for I have often seen the zodiacal light $180^{\circ}$ off the sun. This is no proof against M. H.'s other idea that the two tails curve round and meet; but is there anything in M. H.'s observations contrary to the generally received theory of the zodiacal light? This is that it is not a ring, but a somewhat lens-shaped disc of light, brightest and thickest at its centre (at the sun), and gradually growing thinner and less dense, till it seems to vanish some distance beyond the earth's orbit. Its thickness at its centre would therefore be $60,000,000$ miles, or more, according to M. H.'s observation. The circumstance that he could not see it more than $177^{\circ}$ off the sun might very likely be accounted for by the milky way obscuring it there.

West Hendon House, Sunderland, Feb. 10

\section{The Meteoric Shower}

THE shower of meteors on the night of Nov. 27 last year was evidently well seen in Europe, as I had anticipated, but no notice seems to have been takell of the shower on the night of the 24 th. On that night there was an equally fine display in Jamaica, from about the same radiant point; the night of the $25^{\text {th }}$ was cloudy, and only a few meteors were seen on the vight of the $26 \mathrm{th}$, which was ciear; and the shower on the 27 th was simply a repetition of the shower on the $24^{\text {th }}$; but on both occasions the numbers seen here were somewhat less than in Europe.

These meteors must therefore form two almost distinct bands passing round the sun, which their association with the comet of Biela renders particularly interesting; it is just possible that these two bands intersect, and that one part of the comet belongs to one band and the other part to the other, and that they came into notice and actual contact about the same time in the year 1846 , and of course afterwards separated.

$$
\text { Jamaica, Jan. } 5
$$

MaXivell Hali

\section{Maupertius on the Survival of the Fittest}

Considering that the theories of Darwin and Spencer are among the most important additions ever made to human knowledge, it seems to be a matter of much interest to trace out any occasional glimpses which previous philosophers may have had of the Principles of Natural Selection. In a long note appended by Lord Bolingbroke to his fourth essay concerning Authority in matters of Religion (octavo edition of the Philosophical Works, 1754, vol. ii. p. 253; quarto edition, 1754, vol. iv. p. 255), he reviews a Memoir by Maupertius printed in the History of the Royal Academy of Berlin, for the year 1746. Speaking of the appearances of design, Lord Bolingbroke says :- "Mr. Maupertius proceeds, and admits, but admits, as it were, for argument's sake alone, that the proportion of the different parts and organs of animals to their wants carries a more solid appearance; and he judges that they reason very ili who assert that the uses to which these parts and organs are applied, were not the final causes of them, but that they are so applied because the animal is so made. Chance gave eyes and ears; and since we have them we make use of then to see and hear. He thinks, however, it may be said, that chance having produced an immense number of individuals, those of them whose parts and organs were proportioned to their wants, have subsisted, whilst those who wanted this proportion have perished and disappeared. Those who had no mouth, for instance, could not eat and live; those who wanted the organs of generation could not perpetuate their species; and thus from the present state of things theists draw an argument which will appear falla cious when it is applied to the possible original of things."

I am not aware that notice has been drawn to this distinct allusion to the survival of the fittest. So far as regards the introduction of the notion of chance the statement is no doubt erroneous.

Manchester, Feb. I2

W. Stanley Jevons

\section{"Diathermanous" or "Transfervent"}

THE words "transfervent" and "transfervency" are similar in form to "transparent" and "transparency," and clearly convey their meaning to those who cannot trace them to their source. In number of syllables, also, and in sound are they not more English, or as a Greek might say, less barbarian than words of five, six, or seven syllables which are coined directly from the Greek, but which do not suit so well the Saxon tongue?

W. G. ADAMS

\section{Flight of Projectiles-A Query}

I SHALL feel thankful to any of your numerous mathematical correspondents who will kindly favour me with a simple formuia for determining the deflection in the flight of a leaden cylindroconoidal projectile-the time of flight of which is knowncaused by wind of known force acting at different angles to the vertical plane of the trajectory, with an application of the formula to the following cases. Any other cause of deviation, such as that due to rotation, \&c., may be neglected :-

Suppose the bullet to be $\mathrm{I} \cdot 27$ " long, and its diameler ' $447^{\prime \prime}$, weight $480 \mathrm{grs}$. and the wind to be of force 4 , approximate pressure 4 lbs. per square inch, what is the deviation?

1. When the wind acts at right angles to the trajectory?

2. When it acts at any angle less than a right angle, say $45^{\circ}$ ?

School of Musketry, Hythe, Feb. Io ROBERT REID

\section{ON ACTION AT A DISTANCE*}

WE have now arrived at the great discovery by Örsted of the connection between electricity and magnetism Örsted found that an electric current acts on a magnetic pole, but that it neither attracts it nor repels it, but causes it to move round the current. He expressed this by saying that "the electric conflict acts in a revolving manner."

The most obvious deduction from this new fact was that the action of the current on the magnet is not a push-and-pull force, but a rotatory force, and accordingly many minds were set a-speculating on vortices and streams of æther whirling round the current.

But Ampère, by a combination of mathematical skill with experimental ingenuity, first proved that two electric currents act on one another, and then analysed this action into the resultant of a system of push-and-pull forces be tween the elementary parts of these currents.

The formula of Ampere, however, is of extreme complexity, as compared with Newton's law of gravitation, and many attempts have been made to resolve it into something of greater apparent simplicity.

I have no wish to lead you into a discussion of any of these attempts to improve a mathematical formula. Let us turn to the independent method of investigation employed by Faraday in those researches in electricity and magnetism which have made this institution one of the most venerable shrines of science.

No man ever more conscientiously and systematically laboured to improve all his powers of mind than did Faraday from the very beginning of his scientific career. 